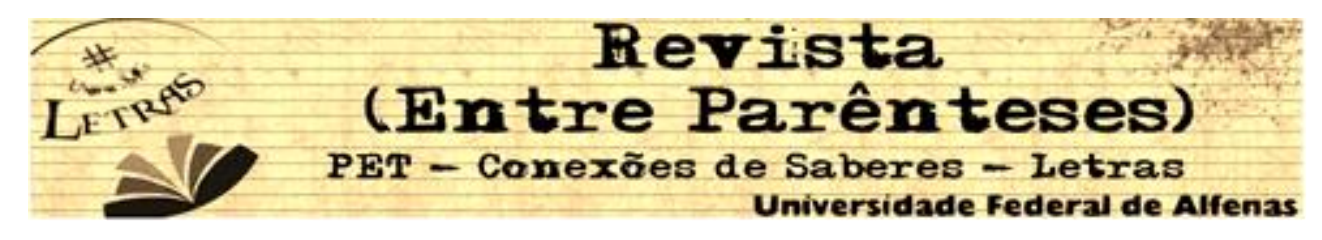

\title{
NOÉMIA DE SOUSA, A “CANTADORA DOS ESQUECIDOS” NA MOÇAMBIQUE COLONIZADA (1948-1951)
}

\author{
Alice Aparecida de Carvalho ${ }^{1}$ \\ Graduanda Universidade Federal de Alfenas - UNIFAL-MG \\ (alice.ecilac@gmail.com) \\ Elaine Ribeiro ${ }^{2}$ \\ Universidade Federal de Alfenas - UNIFAL-MG \\ (elaine.ribeiro@unifal-mg.edu.br)
}

\begin{abstract}
Resumo: O objetivo do artigo é analisar um conjunto de seis poemas produzido entre os anos de 1948 e 1951 pela escritora moçambicana Noémia de Sousa. O elo entre esses poemas se compõe no motivo que Ihes é afim: a denúncia bradada da situação colonizada dos trabalhadores moçambicanos. É essa situação denunciada nos poemas "Patrão", "Magaíça", "Zampungana", "Cais", "Moças das Docas" e, por fim, "O homem morreu na terra do algodão", portanto, o nosso tema de análise.
\end{abstract}

Palavras-chave: Noémia de Sousa; Poesia de denúncia; Trabalho Forçado; Moçambique Colonial.

Abstract: This paper examines a set of six poems produced between the years of 1948 and 1951 by the Mozambican poet Noémia de Sousa. The connection between these poems is the denunciation of the difficult situation of the Mozambican workers in context of Portuguese Colonialism. It is this situation denounced in the poems "Patrão", "Magaíça", "Zampungana", "Cais", "Moças das Docas", and "O homem morreu na terra do algodão", therefore, our theme of analysis.

Keywords: Noémia de Sousa; Protest Writing; Forced Labour; Colonial Mozambique.

Resumen: El objetivo del presente artículo es analizar un conjunto de seis poemas producidos entre los años 1948 y 1951 por la escritora mozambiqueña Noémia de Sousa. El enlace de los poemas seleccionados se da por el tema: la denuncia de la situación colonizada de los trabajadores mozambiqueños. Es esta la situación revelada en los poemas "Patrão", "Magaíça", "Zampungana", "Cais", "Moças das Docas" y "O homem morreu na terra do algodão", componiendo nuestro objeto de estudio.

Palabras-clave: Noémia de Sousa; Poesía de protesta; Trabajo forzado; Mozambique Colonial.

[...] A literatura confirma e nega, propõe e denuncia, apoia e combate, fornecendo a possibilidade de vivermos dialeticamente os problemas. Por isso é indispensável tanto a literatura sancionada quanto a literatura proscrita; as que os poderes sugerem e as que nascem dos

\footnotetext{
${ }^{1}$ Graduanda do curso de História da Universidade Federal de Alfenas - UNIFAL-MG.

2 Doutora em História Social pela Universidade de São Paulo, professora de História da África da Universidade Federal de Alfenas - UNIFAL-MG.
} 


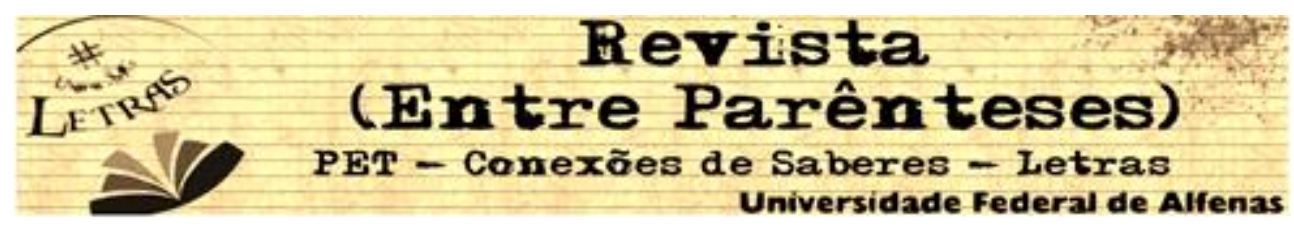

movimentos de negação do estado de coisas predominante." - Antônio Cândido

A obra poética de Noémia de Sousa é uma dessas que Antônio Candido aponta como nascentes da negação do estado de coisas. A poeta moçambicana vem denunciar a opressão colonial em seus vários aspectos, é uma literatura socialmente engajada, sendo possível de ser assim compreendia se relacionada ao seu contexto.

No seu livro Lutar por Moçambique (1995), o mais importante dos líderes da luta de independência, Eduardo Mondlane aponta Noémia de Sousa como um dos símbolos de oposição ao colonialismo na década de 1940, quando um movimento nacionalista não havia ainda se formado. Para Mondlane, Noémia de Sousa e José Craveirinha teriam sido intelectuais notáveis que fizeram a denúncia e a resistência à violência colonial motivos de suas poesias, posto que naquele momento a ação de resistência era limitada e se resumia à literatura engajada. ${ }^{3}$

É preciso indicar que mesmo destacando no presente artigo a sua função de denúncia, a poesia de Noémia de Sousa é, sobretudo, uma expressão de arte, coisa que não negligenciamos ou ignoramos. Como uma expressão artística, possuidora de características que the são distintivas, procuramos apoio, para empreender tal análise necessária, em estudiosos da literatura como Alfredo Bosi e Antônio Candido.

\footnotetext{
${ }^{3}$ Noémia de Sousa é ainda considerada a mãe dos poetas moçambicanos. O escritor Nelson Saúte, conterrâneo da poeta, no ensaio publicado na primeira edição moçambicana da obra Sangue Negro de Noémia, em 2011, e revisto para a primeira edição brasileira de 2016, afirmou: "Costumo dizer que Noémia de Sousa faz parte dos meus antepassados literários. Digo-o com inescondível afeto. Não há, não pode haver, um privilégio maior do que amar esta mulher a quem hoje (re)apresento e de quem tenho o privilégio de chamar "Mãe". Não só porque ela é, como diz a lenda, a Mãe dos poetas moçambicanos, mas porque entre nós há muito que o afeto e a amizade perderam fronteiras e fundaram verdadeiros laços de família. O que permanece, estou certo, é o espanto sempre que a releio. Regresso incauto ao menino de 15 anos que, suponho, nunca deixarei de o ser. [...] Quem seria essa mulher que se escondia no nome de poeta Noémia de Sousa? - interrogou-se o menino que fui. [...] Noémia de Sousa não constava no meu bornal de amador de poetas. Tinha lido, tinha dito, lá no alto da minha inocência, versos da chamada - e aclamada - poesia de combate. Mas desconhecia em absoluto esta mulher. [...] As buscas começaram imediatamente. Quem era Noémia de Sousa, autora daqueles versos frenéticos, daqueles versos longos e belos." (SAÚTE, 2016, p. 195-196)
} 


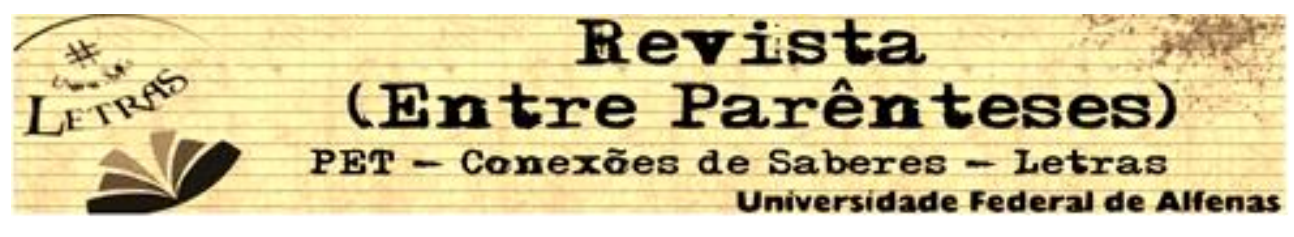

Procurando demonstrar a necessidade da poesia em tempos contemporâneos, Bosi assinala determinadas funções que a poesia cumpre e que a tornam mesmo indispensável. Argumentará o autor que a poesia desempenha um papel fundamental de estímulo à reflexão a medida que "a linguagem-poesia permite que as coisas ganhem um sentido público e comunicável na teia intersubjetiva". (BOSI, 2013, p. 9) A poesia carrega a promessa de delimitar, no turbilhão de informações e processos, o que antes era borrão, ou amontoado; a poesia faz ver.

Isto posto, não lidariam os versos de Noémia de Sousa que se seguem, com essas pessoas que no cotidiano se tornavam, juntas de suas experiências, desfocadas?

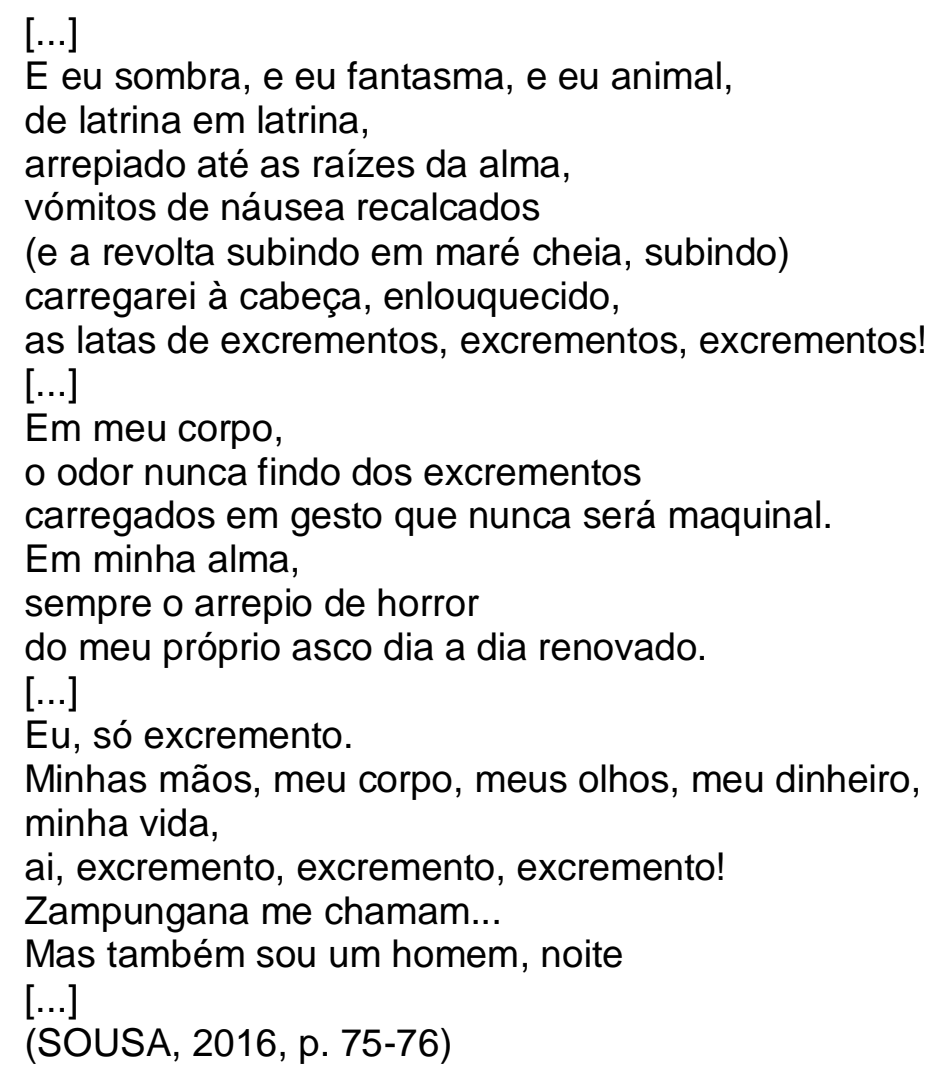

Nesse processo de fazer próximo e visível o que se turva na ordinariedade do dia a dia, Noémia de Sousa não indicaria uma realidade latente, mas naturalizada 


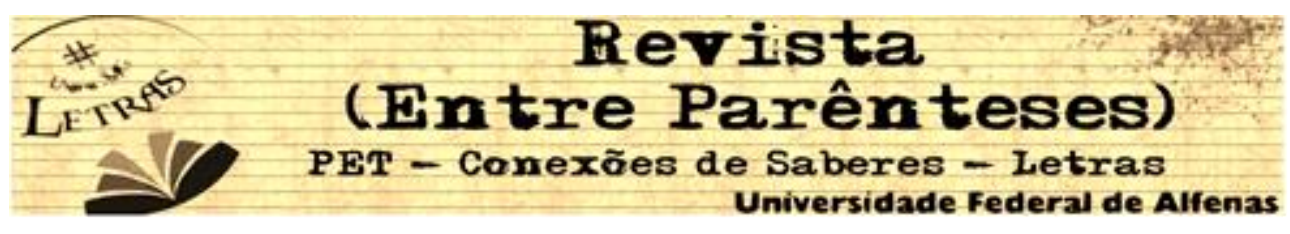

a respeito da figura do zampungana, a qual o poema alude? - "Noémia de Sousa foi quem soltou o primeiro canto da tragédia nocturna dos negros que trabalham na remoção dos dejectos da população dos subúrbios: os zampunganas", responderia o poeta José Craveirinha (2000, p. 101). "A poesia [assim devolveria] corpo e alma, forma e nome ao que a máquina social já dera por perdido". (BOSI, 2013, p. 16).

Todavia, é também Bosi que nos indica a importância de analisar e se aperceber dos mecanismos estrategicamente utilizados pelo escritor para compor a poesia e, consequentemente, expressar-se: "O som que se reitera na rima, o ritmo que se produz no reforço da sílaba tônica, a palavra que volta, o metro que ordena 0 padrão musical do poema significam, mimetizam, exprimem o movimento que vai da intuição às coisas e da paixão à figura outro." (BOSI, 2013, p. 21-22)

Igualmente é Alfredo Bosi quem singelamente indica a relação entre poesia e oralidade, quando manifesta que muito certamente a poesia esteve presente antes mesmo da escrita. Ao sinalizar para essa origem da poesia que independe da escrita, a proposta bosiana alarga a própria categoria de poesia, de modo a não restringi-la apenas ao gênero literário escrito e aproximá-la da oralidade, na qual o conhecimento habita na mente humana, fazendo-se a escrita apenas suporte deste.

Hampaté Bâ (2010), procurando dilucidar a oralidade, indica que a tradição oral abarca a dimensão do conhecimento, da ciência natural, da arte, da história, do religioso, do lúdico e que sempre a ela se retornará, a oralidade foi estrutural em grande parte das sociedades africanas e as tradições orais eram seu veículo de continuidade. Se contemporaneamente a tradição oral já não assume a primazia de antes, deve-se isso ao processo desestruturador e violento do colonialismo, porém, ainda assim, ante a imposição da escrita, ela se faz presente em outras formas, como no próprio texto escrito, e, como enfatiza o filósofo malinês, é indispensável os estudos das tradições orais à compreensão das experiências históricas africanas.

Jan Vansina procura atentar para a não simplificação das sociedades orais em apenas sociedades na qual ausenta-se a escrita, sua atenção se volta para o 


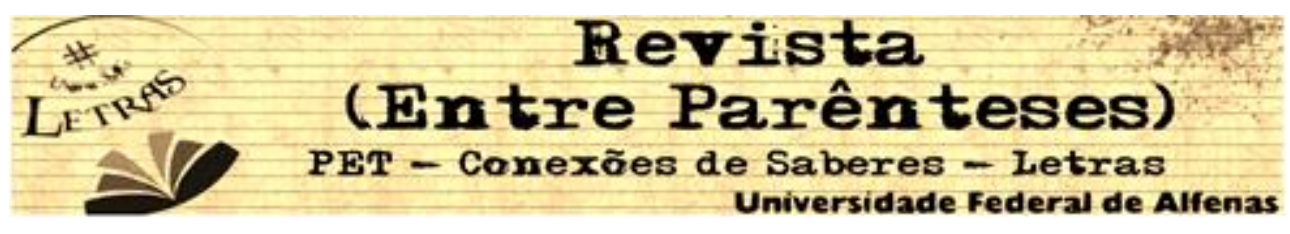

poder da palavra: o discurso possui, nessas sociedades, um valor muito específico, argumenta o historiador belga: "[...] Uma sociedade oral reconhece a fala não apenas como um meio de comunicação diária, mas também como um meio de preservação da sabedoria dos ancestrais, venerada no que poderíamos chamar de elocuçõeschave, isto é, a tradição oral [...]". (VANSINA, 2010, p. 140) O autor apreende e relaciona a tradição oral à memória coletiva que procuraria se explicar a si mesma, conservando-se tal explicação nas tradições orais, daí advém a necessidade de o pesquisador se acercar dos modos de pensar - e diríamos nós de fazer - de uma sociedade para então tencionar interpretar suas tradições. Como historiador, Vansina aproxima-se das tradições orais, compreendendo-as como obras literárias e não dispensa sua análise por esse viés, o que inclui estudar a sociedade que as produziu e transmitiu e a percepção de mundo que contempla o conteúdo desse tipo de expressão.

Parece-nos, por tudo isso, que a produção literária, incluindo a sua dimensão da oralidade, é essencial ao desenvolvimento e desencadeamento de movimentos de resistência que viriam a se configurar em Moçambique nos tempos coloniais, quando Noémia de Sousa "...escrevera apenas durante três anos, o bastante para incendiar o rastilho da poesia que reivindicava a personalidade dos oprimidos, que fundava a literatura dos marginalizados. Tudo isto entre 1948 e 1951". (SAÚTE, 2016)

É por meio da literatura que intelectuais e escritores africanos vão denunciar as violências do colonialismo e conclamar para a resistência a ele, por isso mesmo as produções literárias desse contexto tornam-se frequentemente fonte para os estudos históricos que buscam compreender realidades que se constituíram e se desenvolveram no período colonial.

Além disso, compreender o processo histórico do colonialismo português em Moçambique e a partir de um prisma das pessoas comuns é estar de acordo com a vertente historiográfica que ficou conhecida como "história vista de baixo", 


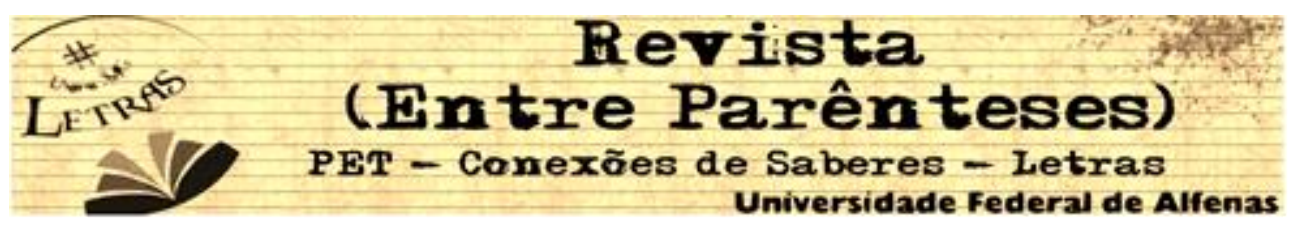

especialmente relacionada à produção do historiador inglês E.P. Thompson, que centrou sua atenção no estudo das pessoas comuns, que poderiam ser compreendidas como indivíduos ou grupos cujas experiências cotidianas foram ignoradas na constituição de uma outra história, que já não desperta mais o interesse do historiador. Thompson propunha considerar a agência desses grupos como integrantes e constituintes dos processos históricos, todavia apontou para a necessidade de compreender essas experiências e agências em seus próprios contextos e peculiaridades. (SHARPE, 1992)

Neste sentido, a poesia de Noémia de Sousa manifesta indícios importantes à compreensão e apreensão da experiência daquelas pessoas recrutadas para desempenhar os piores trabalhadores na então Moçambique colonial. Conforme Arlindo Chilundo, o principal objetivo da colonização portuguesa consistia na exploração da mão de obra moçambicana, destarte esse propósito marcou a experiência do domínio colonial. (CHILUNDO, 1999)

Eleger a poesia de Noémia de Sousa para compreender a situação de exploração colonial, portanto, é potencializar o deslindamento da experiência colonizada a partir das projeções de imagens de homens e mulheres explorados em espaços variados: em cada um dos poemas, a poeta constrói e apresenta personagens que procedem da experiência histórica, tencionando expor suas lutas cotidianas, as violências sofridas, a dignidade perdida, os sonhos decompostos.

Seus poemas trazem à vista personagens e espaços profundamente elencados com a experiência histórica do trabalho no regime colonial. Em "Patrão", por exemplo, Noémia denuncia a violência física e simbólica que sofre uma pessoa em situação de trabalho forçado, aponta para o seu papel essencial na construção dos espaços urbanos, mas também sua atuação nos espaços rurais:

ah patrão, eu levantei

esta terra mestiça de Moçambique

com a força do meu amor,

com o suor do meu sacrifício, 


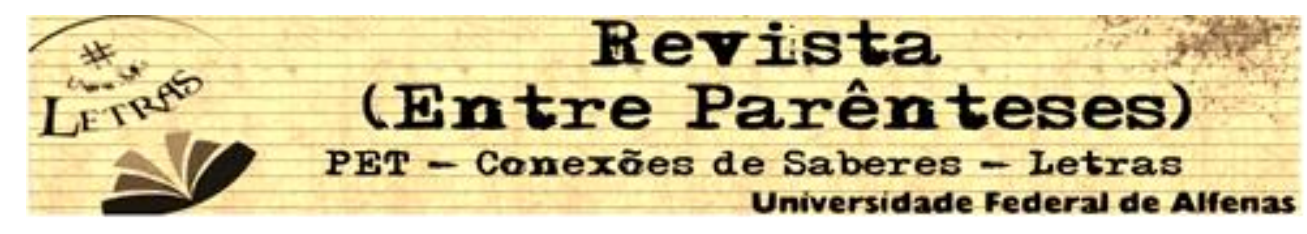

com os músculos da minha vontade!

Eu levantei-a, patrão!

pedra por pedra, casa por casa,

árvore por árvore, cidade por cidade,

com alegria e com dor!

Eu a levantei!

Se teu cérebro não me acredita,

pergunta à tua casa quem fez cada bloco seu,

quem subiu aos andaimes,

quem agora a limpa e a põe tão bonita,

quem a esfrega e a varre e a encera...

Pergunta ainda às acácias vermelhas e sensuais

como os lábios das tuas meninas,

quem as plantou e as regou,

e, mais tarde, as podou...

Pergunta a todas essas largas ruas citadinas,

simétricas e negras e luzidias,

quem foi que as alcatroou,

$[\ldots]$

Pergunta quem morre no cais

todos os dias - todos os dias! -,

para voltar a ressuscitar numa canção...

E quem é o escravo nas plantações de sisal

e de algodão,

por esse Moçambique além...

Mas essa personagem que se lamenta, também traz no seu lamento a promessa de um retorno:

E tu bate-mês, patrão meu!

Bates-me...

E o sangue alastra e há de ser mar...

Patrão, cuidado,

que um mar de sangue pode afogar

tudo... até a ti, meu patrão!

Até a ti...

(SOUSA, 2016, p. 70-72)

Em "Magaíça" a personagem é o migrante, o "mamparra" recém-chegado que retorna desiludido da África do Sul, para onde foi em busca de trabalho nas minas de ouro e das oportunidades que Ihe foram tiradas na sua terra moçambicana. Noémia de Sousa nos dá um lampejo da situação do trabalhador em terras sul-africanas e

\section{Revista (Entre Parênteses)}

Volume 6, Número 2, 2017 - ISSN 2238-4502 


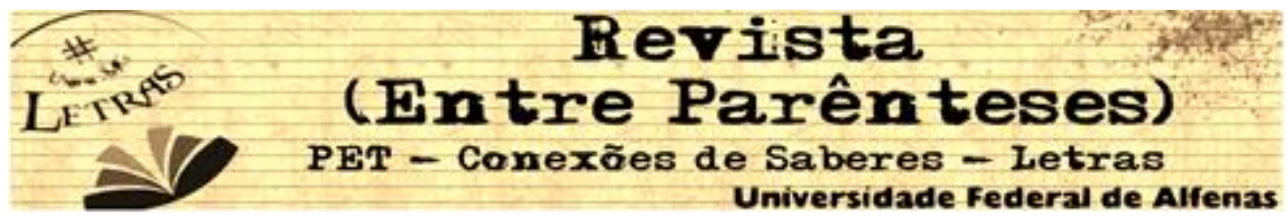

indícios de sua sorte: sua força de trabalho desfrutada, sua saúde perdida, seus sonhos olvidados:

A manhã azul e ouro dos folhetos de propaganda

engoliu o mamparra,

entontecido todo pela algazarra

incompreensível dos brancos da estação

e pelo resfolegar trepidante dos comboios

Tragou seus olhos redondos de pasmo,

seu coração apertado na angústia do desconhecido,

sua trouxa de farrapos

carregando a ânsia enorme, tecida

de sonhos insatisfeitos do mamparra.

E um dia,

o comboio voltou, arfando, arfando...

oh nhanisse, voltou.

e com ele, magaíça,

de sobretudo, cachecol e meia listrada

e um ser deslocado

embrulhado em ridículo.

Às costas - ah onde te ficou a trouxa de sonhos, magaíça?

trazes as malas cheias do falso brilho

do resto da falsa civilização do compound do Rand.

E na mão,

magaíça atordoado acendeu o candeeiro,

à cata das ilusões perdidas,

da mocidade e da saúde que ficaram soterradas

lá nas minas do Jone...

A mocidade e a saúde,

as ilusões perdidas

que brilharão como astros no decote de qualquer lady

nas noites deslumbrantes de qualquel City.

(SOUSA, 2016, p. 73-74)

Já o ambiente de "Cais" deposita o leitor nos cais, docas e portos.

O cais é um gigante,

sugando esforços, violentamente...

O cais negro e chispante

é a nossa vida e o nosso inferno 


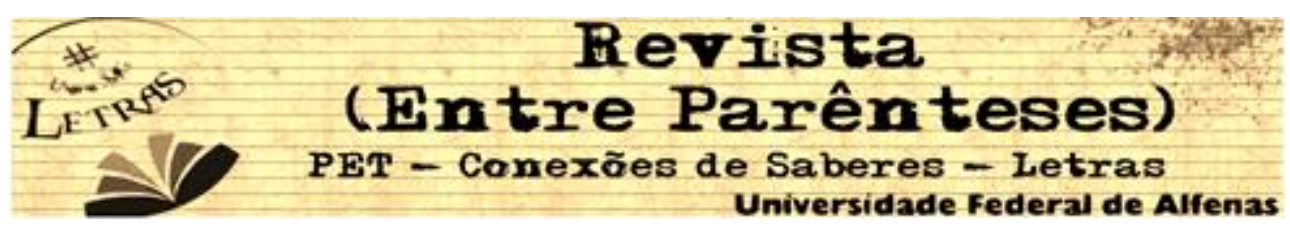

Os personagens são os estivadores, os carregadores de fardos pesados e "infindos" que trabalham nos portos, explorados "cantam" sua labuta.

Sobre os nossos ombros potentes, retesados, o suor rasgou nascentes e abriu leito entre os nossos músculos encordeados...

E "aí, pachiça!", os fardos pesados como o mundo, multiplicam-se e crescem espantosamente, cada vez mais...

[...]

Nos nossos olhos cansados, há desesperos e revoltas.

E com um último resto esfarrapado de esperança, interrogamos ansiosamente o mar.

Mas o mar - ai! o mar! - continua fechado à inquieta interrogação do nosso olhar...

E os fardos, sempre mais pesados...

E o Sol, como um milhão de agulhas picando nosso dorso luzente de suor...

e nada mais.

Mar.

Se tu nos abandonaste nesta hora, quem nos dará agora, coragem, mar?

Quem nos emprestará força e esperança para continuar?

Para os despercebidos socialmente, Noémia de Sousa nos lembra que a canção, assim como a sua poesia, é a melhor parceira para exprimir a dor e buscar forças para a resistência - parafraseando Bosi (2013, p. 20-21) - ela faz isso "aliando num só lance verbal sentimento e memória, figura e som. [...] o seu regime é o da densidade, que se alcança pela inumerável combinação de sons, ritmos, palavras":

Ah, só tu canção sem fim dos desesperados, só tu, voz da nossa alma! Ergue-te a pino, Ergue-te a prumo sobre o pó, canção, 


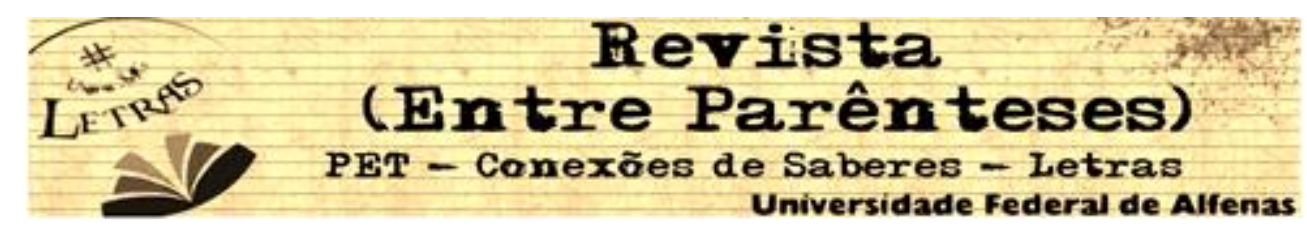

sobre o cais infernal, sobre os fardos nunca findos, sobre o egoísmo da cidade cruel e imensa, dormindo ao Sol - farta e contente sobre o velho mar cansado, sobre o mundo, sobre a vida...

E canta!

Cada vez mais forte,

Canta a canção escrava do nosso destino!

Abafando todos os ruídos, alheio a todas as fraquezas, canta coração!

Canta, canção dorida!

Canta!

(SOUSA, 2016, p. 77-78)

Também personagens que se movimentam nas docas, as mulheres que lá trabalham, são delineadas nos versos de "Moças das Docas". Aí a poeta apresenta as mulheres afastadas de sua dignidade pela violência cotidiana, esquecidas em sua dor e em seus sonhos findos. Noémia de Sousa traça essas mulheres e os espaços com os quais se relacionam, dando indícios sobre suas experiências com a cidade e com seus outros ocupantes.

Somos fugitivas de todos os bairros de zinco e caniço.

Fugitivas das Munhuanas e dos Xipamanines, viemos do outro lado da cidade com nossos olhos espantados, nossas almas trançadas, nossos corpos submissos e escancarados.

De mãos ávidas e vazias,

de ancas bamboleantes lâmpadas vermelhas se acendendo, de corações amarrados de repulsa, descemos atraídas pelas luzes da cidade, acenando convites aliciantes como sinais luminosos na noite.

Viemos ...

Fugitivas dos telhados de zinco pingando cacimba, do sem sabor do caril de amendoim quotidiano, do doer espáduas todo o dia vergadas sobre sedas que outras exibirão, dos vestidos desbotados de chita, 


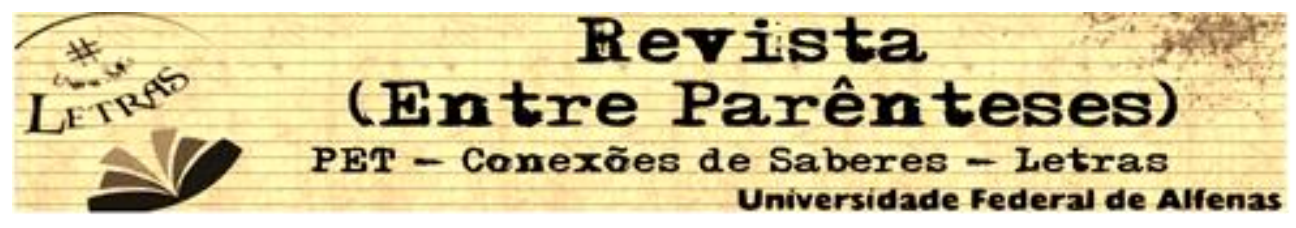

da certeza terrível do dia de amanhã retrato fiel do que passou, sem uma pincelada verde forte falando de esperança.

A coisificação dos seus corpos é denunciada a partir da súplica por esperança de se tornarem mulheres de novo:

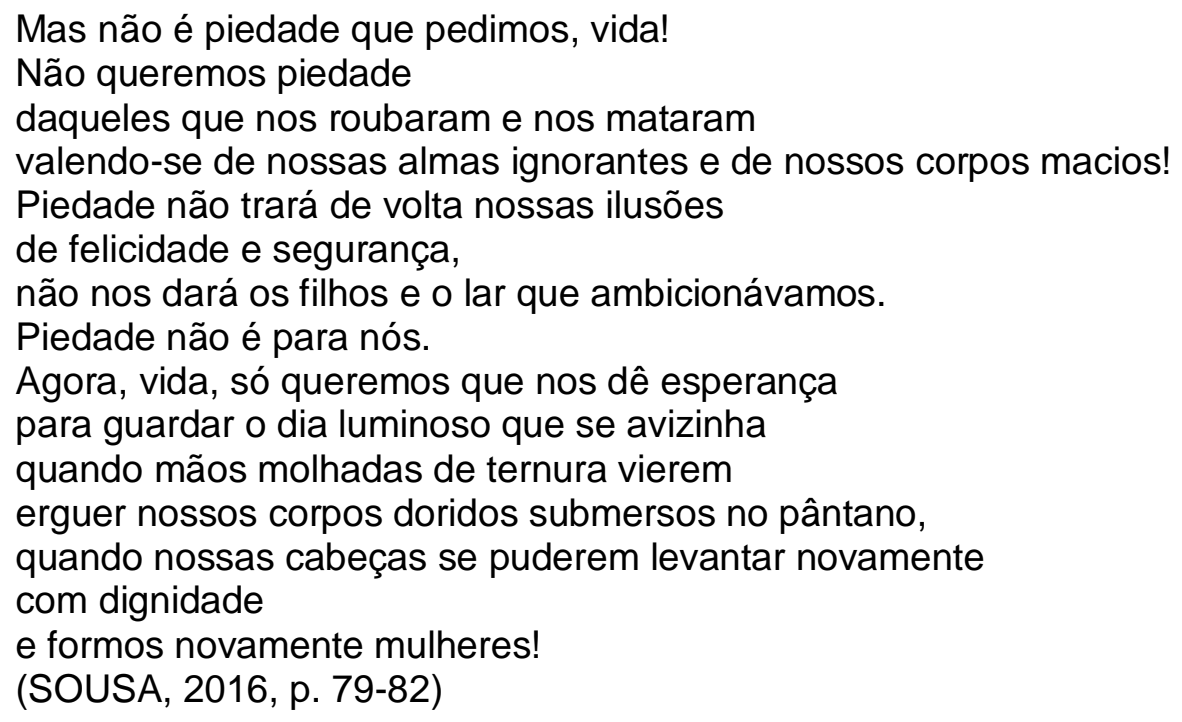

Por fim, em "O homem morreu na terra do algodão", Noémia de Sousa se volta para o trabalho forçado nas plantações de algodão, para a escravidão da população que é explorada e morre por lucros que não serão seus sob o regime de trabalho forçado. Para tanto, utiliza o jogo de cores para projetar sua denúncia - o negro da terra, o branco do algodão e o vermelho do sangue derramado:

Na terra do algodão

a vida foi-se no sangue jorrado

da boca em rictus de amargura

e desilusão

a vida foi-se no sangue jorrado...

Mas o algodão continuou

a florir todos os anos em beleza e brancura...

Suas leves nuvens sedosas

ainda mais brancas se tornaram,

mais brancas que a lua 


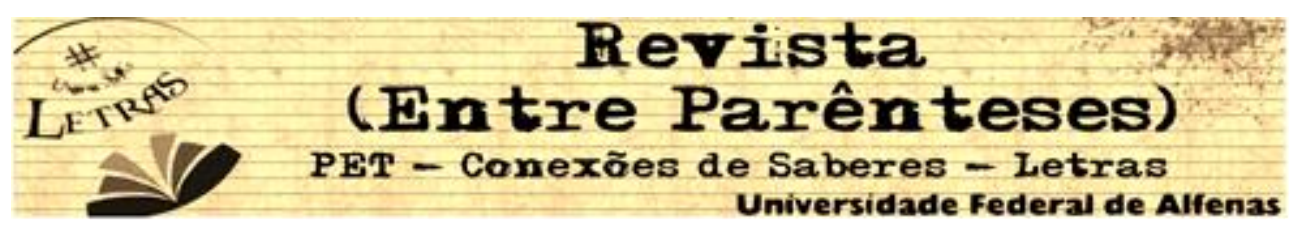

brancas, cruelmente brancas, de brancura luminosa e pura, sem mistura... [...] E nem o sangue jorrado...

Mas vem aí a madrugada, vem aí o sol sangrento da madrugada, entornar o vermelho forte do sangue dos homens bons sobre a terra amaldiçoada dos tiranos...

$E$ as bolas macias do algodão

Vão embeber-se todas, com volúpia; no vermelho do sangue jorrado da boca do homem que morreu escravizado na terra negra do algodão...

(SOUSA, 2016, p. 79-82)

Cabe perguntar: Noémia de Sousa denuncia experiências das quais fora interlocutora? Ou algumas dessas situações the chegavam pelo trabalho que desempenhava na imprensa, onde publicou boa parte de seus poemas, entre outros escritos? Ou faria também referência a eventos, episódios, processos e circunstâncias que apesar de aparentes e indissociáveis da experiência colonial, já tinham sido naturalizadas na paisagem colonizada?

Eduardo Mondlane (1995, p. 93) argumenta que poemas como os que analisamos aqui são "interessantes não tanto por sua força e eloquência, mas antes pelos termos que utilizam para descrever a situação", o que configura a força e a fraqueza do movimento de resistência no tempo de Noémia de Sousa, pois nenhum dos escritores da mesma época, como José Craveirinha e Marcelino dos Santos, "experimentou o trabalho forçado, nenhum deles esteve sujeito ao Código do Trabalho Nativo", por isso escreveram "sobre a situação como expectadores de fora, lendo as suas próprias reações intelectualizadas nas mentes do mineiro e do trabalhador forçado africano".

Fossem os termos contidos nas obras literárias comparados àqueles utilizados nas denúncias dos próprios trabalhadores, seria visível a mudança do tom e o uso de outras imagens para indicar a opressão sofrida:

Metemo-nos no comboio e chegávamos a Sewe, 


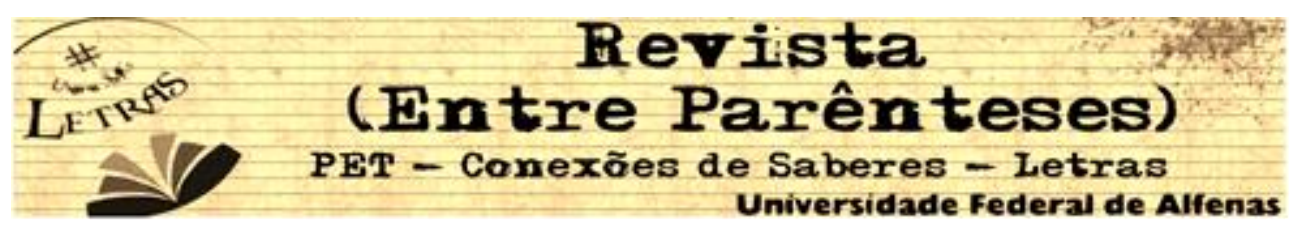

E quando falamos no assunto da comida,

No assunto da comida, eles voltaram as costas.

Nós ouvimos os Portugueses falar de comida,

Falar de comida com as costas voltadas. (VAIL; WHITE, 1984, p. 55)

O excerto é parte de um migodo, ou uma canção, que integra o patrimônio oral dos Chopi, sociedade do sul de Moçambique. É a partir dos migodos ou de sua poesia que os componentes dessa sociedade se manifestam constituintes dos trabalhadores explorados que são objeto dos poemas, como demonstra essa canção, na qual abordam o tema das más condições de trabalho e mesmo, de vida. A denuncia dos métodos violentos de recrutamento forçado de trabalhadores e o descaso dos portugueses que "voltam as costas" para o bem-estar dos recrutados. (VAIL; WHITE, 1984, p. 54-55)

Se não é possível a poesia de Noémia de Sousa projetar a força da imagem que os trabalhadores forçados tinham das "costas voltadas" dos colonizadores, não menos agudas são, porque projetadas de um ângulo diferente, externo, as imagens de "músculos encordeados" dos estivadores do Cais ou das "ancas bamboleantes" e dos "corações amarrados de repulsa" das Moças das docas, ou ainda, do "sangue jorrado da boca do homem que morreu escravizado na terra negra do algodão". A cena projetada no migodo junto à poesia de denúncia de Noémia de Sousa potencializam a nossa compreensão da dura situação dos colonizados africanos, pois produzem um quadro mais detalhado da realidade colonial.

Apreciamos, portanto, os poemas de Noémia de Sousa como denúncias, porque em nosso entender a autora também assim os inferia - Noémia não pretendeu publicar sua obra poética em um livro, considerava antes que seus poemas deveriam ser publicados em jornais e antologias, de modo que pudessem ser associados ao contexto do qual provinham e denunciavam, e chegar, efetivamente, à um público maior. (NOA, 2016) Dessa forma, a literatura figura como artifício importante de denúncia e luta, no contexto do colonialismo. 


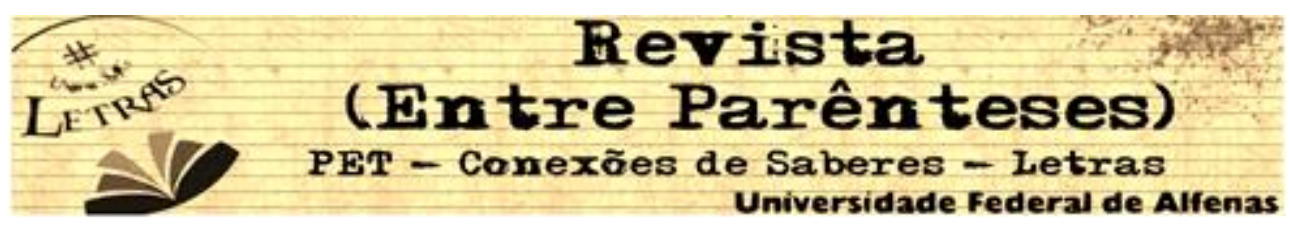

Provavelmente por também compreender da mesma maneira, o poeta José Craveirinha (2000, p. 102) chamou Noémia de Sousa de "cantadora dos esquecidos".

\section{Referências}

BÂ, A. Hampaté. A tradição viva. In: KI-ZERBO. História Geral da África. I: Metodologia e pré-história da África. 2 ed., Brasília: UNESCO, 2010, p. 167-212.

BOSI, Alfredo. Entre a literatura e a história. São Paulo: Editora 34, 2013.

CANDIDO, A. O direito à literatura. In: . Vários escritos. 3a . ed. São Paulo: Duas cidades, 1995.

CHILUNDO, A. et al. (Org.) História de Moçambique: Moçambique no auge do colonialismo, 1930-1961. 2ª . ed., Maputo: Livraria Universitária, 1999.

CRAVEIRINHA, José. Noémia de Sousa. In: LARANJEIRA, Pires (Org.) Negritude africana de Língua Portuguesa. Textos de Apoio (1947-1963). Braga: Angelus Novos, 2000, p. 100-103.

MENDONÇA, Fátima. Moçambique, Lugar para poesia. In: SOUSA, Noémia. Sangue Negro. São Paulo: Editora Kapulana, 2016.

MONDLANE, Eduardo. Lutar por Moçambique. Maputo: Colecção Nosso Chão, 1995.

NEWITT, Malyn. História de Moçambique. Portugal: Publicações Europa-América LDA, 2012.

NOA, Francisco. Noémia de Sousa: a metafísica do grito. In: SOUSA, Noémia. Sangue Negro. São Paulo: Editora Kapulana, 2016.

PENVENNE, J. Trabalhadores de Lourenço Marques (1870-1974). Maputo: Arquivo Histórico de Moçambique, 1993.

RUI, Manuel. Eu e o outro - O invasor ou Em poucas três linhas uma maneira de pensar o texto. In: MEDINA, Cremilda. Sonha Mamana África. São Paulo: Epopéia, 1987, p. 308-310. 


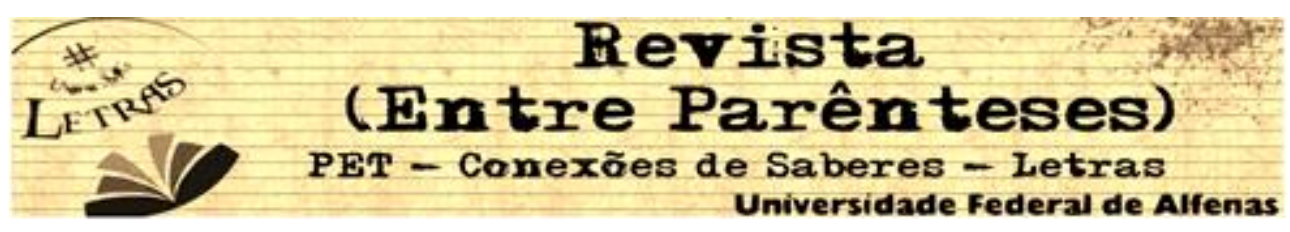

SAÚTE, Nelson. A mãe dos poetas moçambicanos. In: SOUSA, Noémia. Sangue Negro. São Paulo: Editora Kapulana, 2016.

SHARPE, Jim. A história vista de baixo. In: BURKE, Peter (Org.). A escrita da história: novas perspectivas. São Paulo: Ed. da UNESP, 1992, p. 39-62.

SOUSA, Noémia de. Sangue Negro. São Paulo: Editora Kapulana, 2016.

VAIL, L. WHITE. L. Formas de resistência: canções e noções de poder na colónia de Moçambique. Revista Internacional de Estudos Africanos. n.2, jun./dez., p. 9-62, 1984.

VANSINA, A. A tradição oral e sua metodologia. In: KI-ZERBO. História Geral da África. I: Metodologia e pré-história da África. 2 ed., Brasília: UNESCO, 2010, p. 139166. 